\title{
Research on the Characteristics of Post-90s Employees in the Financial Industry and Companies' Response Strategies
}

\author{
Yuanmeng Zhang \\ ${ }^{1} X i$ 'an jiaotong Liverpool university, Suzhou, Jiangsu, 215000, China. \\ *Corresponding author. Email:13898804672@163.com
}

\begin{abstract}
Post-90s teenagers have gradually become the main force in all fields. Compared with post-70s and post-80s people, post-90s have some different characteristics. They grow up in an era of peace and fast development so they have opportunities to accept better education and do not need to worry about problems of existence. Therefore, their values and behaviors are different from post-70s and post-80s. This paper mainly aims to explore changes that company needs to make on post-90s staff management especially in the financial industry. Through the method of theoretical analysis, the first step is to research on the traits of post-90s employees and competence that are needed in the financial industry. It has been found that post-90s are knowledgeable, full of opinions and have the ability of learning fast but they are selfcentered and eager for attention. Some of these traits are consistent with talents' standards in financial companies. Next, for the weakness and strength of post-90s employees, this paper puts forward some practical suggestions on how to manage the post-90s employees well in response to the post-90s' requirement especially in financial industry. Company should tend to be people-oriented, objective, fair and with good corporate culture and atmosphere.
\end{abstract}

Keywords: Post-90s, Employees'characteristics, Finance companies, Staff management.

\section{INTRODUCTION}

Nowadays, post-90s teenagers have gradually become the main force in all fields. Because compared with post-70s and post $80 \mathrm{~s}$, the life and educational backgrounds of post-90s have improved a lot, post-90s teenagers are usually knowledgeable, full of minds, unique and self-centered. They contact comprehensive and multi-cultural education, and experience advanced technology from an early age. It is generally believed that most of post-90s employees are more creative and capable but their desire for success usually make them lack of team spirits and patience. Post-90s employees are totally different from post-70s and post-80s, and traditional management model cannot meet contemporary employees' requirements, therefore, it is necessary to establish a new management model, especially in the competitive financial market. Brooks said that in the fiercely competitive corporate market, war for talent can never stop, and high-quality candidates are extremely in shortage [1]. It can be argued that competition in the commercial market is actually the competition of talents. Faced with fierce talent competition, company try to attract and retain qualified financial employees who have the capacity to learn quickly and make right decisions in a short time. In order to achieve this aim, financial companies need to know what young workers want and how to manage them. This paper will analyze the traits of these post-90s employees and changes that can be made by financial firms to encourage post-90s employees to maximize the value of themselves and the profit for the companies.

\section{REQUIREMENTS FOR EMPLOYEES IN THE FINANCIAL INDUSTRY}

\subsection{Professional Competence}

Professional competence not only refers to professional knowledge about finance and economy but also includes true and fair view. First of all, financial workers should have the capacity to understand financial reports like cash flow, income sheet and balance sheet, and also to calculate the optimal way to do investment with limited funds. It is necessary for financial employees to supply professional service for their clients. In addition, true and fair view means that when they are making 
decisions, they should be fact-oriented, fair and just, and not confused by money. Financial employees deal with huge amount of money nearly every day. Facing the temptation of interest, employees may have some wrong and illegal behaviors, for example, manipulating data on the reports or conceal the truth not disclose it. These behaviors are all prohibited.

\subsection{Continuous Learning Ability}

Continuous learning ability means that employees are able to continue to learn new knowledge during their lifetime. With the development of economy and society, new knowledge and ideas emerges endlessly. Continuous learning can make an effect on employees' changeefficacy which adjust employees' contextual performance positively [2]. As a qualified financial worker, it is significantly essential to learn new financial rules and policies such as new exchange rates, accounting rules, company tax policies and stock market transaction. No one can learn all skills and knowledge before starting to work. Therefore, owning the ability of continuous learning is necessary. Applying the new knowledge learned to actual work is a standard to test the ability of an employee. There are still a lot of managers and even senior managers using the old-fashioned knowledge to manage a project or employees. It is obvious that it is inefficient and cannot keep up with the times. Economy is a system that is constantly changing and has connection with various industries. Learning different products and new projects can bring more commercial opportunities and profits to companies. What's more, continuous learning can have more creative ideas and is helpful to self-development.

\subsection{Strong Resistance to Pressure}

In the financial world, every decision and every project have risks. It is impossible to avoid risks but to make the risks lowest. Generally, employees will take responsibility for all consequences. It is necessary for financial employees to learn how to resist pressure and keep optimistic. Nowadays, more and more financial employees have 996 lifestyle which is working from 9 am to $9 \mathrm{pm}$ from Monday to Saturday. Working overtime has become a fashionable trend. Due to overloaded work and lack of private time, many young people have problems of poor skin, hair loss and insomnia. Anxiety and pressure generated from work will affect their work efficiency and mood. Thus, companies prefer to employ the employees who can deal with stress well.

\subsection{Communication and Coordination Skills}

Actually, the power of the team is far greater than the individual. Anyone cannot live without the group. Individual's potential can usually be stimulated by others in a team. Through communication and discussion, some innovative ideas can be come up with. Many financial projects are completed through the cooperation of different departments such as audit department, finance department and leaders. Therefore, the ability of communication and cooperation is a very important traits required by companies.

\section{CHARACTERISTICS OF POST-90S EMPLOYEES}

\subsection{Growth Background}

Due to flourish economy and stable political situation, post -90 s employees usually accept more advanced and completed education, and even can study abroad. Most of them are graduated from world top ranked university. Apart from studying their majors, they generally have a wider range of hobbies such as sport, music and art. They are more fully developed than post-70s and post-80s. Therefore, they have more rich knowledge and open mind, and are more tolerant of new things. Compared with post-70s and post-80s, post-90s employees have bigger ambitions and dream. In addition, most of their family only have one child. It is easy to cause some defects in their personality like capricious, not good at cooperation, selfish and self-centered. It is commonly argued that post-90s do not how to cooperate with others and how to care about others. It is inevitable for them to cause contradictions at work. Moreover, it is general that their resistance of pressure is poor because most of them grow up in a good environment which has enough food, enough resources and no war. They do not need to fight for their future and worry about survival problems. They have not suffered any hardship under the protection of their parents. When they enter the workplace and have to solve anything by themselves, those post-90s employees are usually unbale to bear the burden.

\subsection{Values}

Firstly, different from post-70s and post-80s employees, post-90s employees pay more attention to self-achievement when they find a job. Although they hope to have a high-salary job, they attach importance to job itself. According to Kane, millennials who are full of confidence, ambitions and achievement-oriented prefer to do some challenging work, and even are less afraid to challenge the authority [3]. Moreover, they would like to participate in company decision, and their advice can be respected and adopted. In the course of work, they want to lifting capacity and get ready for the future career development. Most of post-90s worker think they should find suitable job which can provide great room for development. If not, they will choose to quit the job. Secondly, except job itself, they always prioritize the company with great enterprise culture and work environment. Post-90s workers hope for a tidy and comfortable environment in their companies like world 
top 100 companies which have private space, lounge for drinking a cup of coffee or have a chat and gym. It is helpful for them to choose manner of working they like and enjoy their job. The combination of work and rest make them happier and higher efficient. They try to break the traditional working style and break through the limit in the workplace. What's more, in terms of company culture, they refuse to work for the company with unhealthy and unfair culture. Fair competition, respecting female and refusing drinking culture are vitally important factors for company development. In some firms, those who work for the company for many years usually have more rights even if they are unable to keep pace with fast development of society and not qualified for their positions. It causes lots of complains from young employees because their effort cannot receive award.

It is a serious problem to be solved. Moreover, nowadays, world is becoming more and more multicultured and diversified. In order to increase the diversity of company, company should respect and care about employees with different gender, skin, countries and languages. It will make post-90s workers feel accepted and needed.

\subsection{Lifestyles}

Post-90s employees lay emphasis on living quality and hope to enjoy their life after effort. Post-90s employees complain about overtime work and 996's lifestyle which deprival of right to choose their own life. Job is not the whole part of life but is the way to achieve ideal life. They do not want to follow the example of their parents. Compared with post-90s, most post-70s and post-80s people are usually willingly bear the burden of hard work, and spend money on their children and parents, and ignore themselves. Humanized working style are highly praised by young workers because it gives employees more rights and respect. In addition, post-90s employees prefer to have flexible work which do not have limited time and place, and give them more freedom. Especially during pandemic period, online working become more popular. Online working means more and more young people can balance the work and family. They do not need to commute every day and worry about morning peak which leave enough time to educate their children and to enough their own time, and even save some expenses. Overall, post-90s employees also pay attention to their happiness index while they are working.

\section{CHANGES THAT COMPANIES NEED TO MAKE}

With the consideration of characteristics of post-90s employees and requirements for employees in the financial industry, new management should be peopleoriented, fair, objective and with good company culture.

\subsection{People-centered Management}

People-centered management model require leaders care about and understand their employees, and form a fair and warm workplace. Post-90s employees are intelligent, personable and with opinions so they are unwilling to be shaped by traditional and conservative management system. Nowadays, enterprise culture is ruthless and lack of humanistic care so that to some extent, feeling of employees are ignored, and interest of corporate is more than anything else [4]. Instead of just giving an order, post $-90 \mathrm{~s}$ employees prefer equal communication with their leaders and participating in the process of decision-making. The decision-making process should be open and transparent. Leader also need to understand the minds of its employees, their expectation of and how they feel about the firm. In addition, phenomena that employees are promoted according to status should be prohibited. It is hated by young workers and restrain fair competition. Many post70 s and post-80s think they have nothing to worry about, once they are employed by company. Nevertheless, if they are not adequate for their job, they will get the sack no matter how high their positions are. Therefore, every employee needs continuous improvement and learning. What's more, nowadays, there is a fashionable word called 'involution' which means intense competition in the industry and then lead to resource in short supply in the workplace or school. Affected by 'involution', more and more young employees feel stressful and unhappy so company should understand what make them feel pressure and try to solve the problem. It will make employees feel that they are being cared for and listened to. In addition, as for salary and bonus policy, post-90s employees pay more attention to fairness and rationality. Equal and sound remuneration system should be built and improved. Employees' excessive effort and contribution ought to be recognized by company through material reward. For example, many young people like to do some stock investment. Company can give them right to buy their own company's stocks at a lower price as material reward. Reward and bonus encourage employees to make contribution for the company and meanwhile it also reacts with company's development. Thus, in order to practice humanized management well, corporates should pay close attention to salary performance management, material and spiritual motivation, timely communication, and give recognition of employees' value, and increase the sense of achievement[5]. It will have positive effect on enhancing the cohesiveness of companies.

\subsection{Quantitative and Unqualified Assessment}

Profit is not the single standard for performance assessment. Some unqualified performance should also be taken into consideration which can show on the accounting report like effort employees make. Some projects or investment with high degree of difficulty are 
usually hard to achieve. When profit becomes the sole standard of performance, some employees will do some illegal manipulations on the accounting report in order to reach value of expectation. Therefore, it is necessary for company to establish an assessment system with consideration of both quantitative and unqualified factors. It also accords with fair and humanized management model expected by post-90s employees.

\subsection{Construction of Enterprise Culture}

Excellent corporate culture is an essential part of the whole company. It can not only increase the confidence of employees but also promote a sense of belongings and team spirits among employees. First of all, good company culture should be able to strengthen the teamwork between employees but not individualistic heroism. Most post-90s employees are returnees and highly educated so that they are eager to prove that they worthy of respect and trust. It will easily cause goal incompatibility, lack of cooperation and vicious competition between industry. In order to make common purpose come true, it is necessary for company to promote interaction and cooperation between employees and do ideological education before appointed. Moreover, efficient culture construction should not be superficial but some practical strategies. Secondly, company should encourage innovative and creative ideas but not with strange eyes. In general, post90s employees like to make a bold trial and have some conjecture. Mo has suggested that society and company should create an atmosphere that can encourage young people to have the courage to attempt, be adventurous and accept failure so that employees have the chance to transfer knowledge into practical application [6]. It is helpful to maximize the value of employees and earn more business opportunities for companies.

\section{CONCLUSION}

This paper mainly studies the traits of post-90s employees and the measures that company can adopt to manage them well. Firstly, this thesis analyzes what qualities should a qualified financial employee possess and then describes the characteristics that post-90s employees have. Secondly, post-90s employees are double-edged swords so the paper puts forward some efficient advice to help financial enterprises maximize the advantages of post-90s employees. Through analysis, it is easy to conclude that young workers pay more attention to self-development and self-perception, therefore, financial company should implement humanized management model and exercise better care with their employees. Finally, this thesis can help leaders learn about post-90s and know how to manage them. Although this paper gives a detailed analysis of post-90s employees and changes that financial company need to make, there are still some places which are overlooked. In addition, if this field can be attached importance by more and more researchers and especially financial companies in the near future, it will get in-depth development.

\section{ACKNOWLEDGMENT}

I want to acknowledge my parents. They encourage me and make me quite have the courage to write a thesis during the undergraduate period. Next, I want to say thank you to my professor Kishore Sengupta, my thesis advisor Kaylee . From the first draft to the final paper which can be published, she has made much effort.

\section{REFERENCES}

[1] Ashley Brooks. (2019) What is talent management and why is it so important. https://www.rasmussen.edu/degrees/business/blog/ what-is-talent-management/

[2] Budhiraja , S. (2021) Can continuous learning amplify employees' change-efficacy and contextual performance? International journal of manpower. 42, 6: 1144-1158.

[3] Sally Kane. (2019) The common characteristics of millenial professionals https://www.thebalancecareers.com/commoncharacteristics-of-generation-y-professionals2164683

[4] Li, pl. Lu, h. (2019) Research on initiative turnover rate of the post-90s workforce. Journal of human resource and sustainability studies. 2, 12-25.

[5] Li, hj. (2019) Research on humanized management of diversified and compound talents in enterprise human resource management. IN: 4th international social science and education conference (ISSEC 2019). UK.

[6] yuchi mo. The challenges that are faced by innovative and entrepreneurial personnel and the strategies that can be made. Marketing, 2021(31):42-43. 